\title{
Electrochemical Sensor for Ultrasensitive Determination of Atorvastatin Based on Polypyrrole Functionalized Graphene Sheets
}

\author{
Liting Wei ${ }^{*}$, Haiying Yang, Jiao Jiao \\ Department of Applied Chemistry, Yuncheng University, Yuncheng, 044000, China; \\ *E-mail: weiliting_job@163.com \\ doi: $10.20964 / 2018.11 .67$
}

Received: 7 July 2018 / Accepted: 6 September 2018 / Published: 1 October 2018

\begin{abstract}
In this study, polypyrrole functionalized graphene sheets (PPY-GNs) have been used for the first time as a reinforced material for the ultrasensitive detection of atorvastatin by the electrochemistry method. The obtained PPY-GNs were characterized by scanning electron microscopy (SEM) and Fourier transform infrared (FT-IR) spectroscopy. Due toits porous structure, the PPY-GNs- modified electrode has a large effective area, thereby improving the sensitivity of detection. The peak currents of atorvastatin at the GNs-modified glassy carbon electrode (GNs/GCE) and those at the PPY-GNs/GCE are increased dramatically compared to those on the bare GCE. The peak current at the PPYGNs/GCE linearly increases with the increase in the atorvastatin concentration, which ranges from $20 \mu \mathrm{M}$ to $200 \mu \mathrm{M}$. The detection limit of atorvastatin reaches $1.191 \mu \mathrm{M}$ based on the signal-to-noise characteristic $(\mathrm{S} / \mathrm{N}=3)$. The PPY-GNs-based electrochemical sensor was successfully used to detect atorvastatin in tablets with satisfactory results.
\end{abstract}

Keywords: polypyrrole functionalized graphene sheets; polypyrrole; atorvastatin; electrochemical sensor

\section{$\underline{\text { FULL TEXT }}$}

(C) 2018 The Authors. Published by ESG (www.electrochemsci.org). This article is an open access article distributed under the terms and conditions of the Creative Commons Attribution license (http://creativecommons.org/licenses/by/4.0/). 